\title{
Modelo conceitual para criação de jogos voltados para a tomada de decisão em gerenciamento de projetos
}

\author{
George André Alves Freire, Charles Andryê Galvão Madeira \\ Instituto Metrópole Digital - Universidade Federal do Rio Grande do Norte \\ georgefreirebreyahoo.com.br, charleseimd.ufrn.br
}

\begin{abstract}
Project managers need master many areas and being able to make fast and efficient decisions. Such skills normally can be acquired through professional experience and continuing education. In this context, serious games have stood out among the tools for training by their ability to attract and engage. This work proposes a solution to provide games for project management training focused on the decision making process. This conceptual model was successfully tested by experiments with a game, which differs significantly from the existing solutions in the market, especially due to its growth capacity through the participation of the academic community.
\end{abstract}

Resumo. Gerentes de Projeto precisam dominar diversas áreas de conhecimento e estar aptos a tomar decisões com celeridade e acurácia. Tais habilidades são normalmente adquiridas através do exercício da profissão e da educação continuada. Nesse contexto, jogos sérios vêm se destacando entre as ferramentas para treinamento por sua capacidade de atração e engajamento. Neste trabalho é introduzido um modelo conceitual para prover jogos para a educação do gerenciamento de projetos focada no processo de tomada de decisão. Este modelo foi testado com sucesso através de um jogo experimental, se diferenciando das soluções existentes no mercado pela sua capacidade de evolução através da participação da comunidade acadêmica.

\section{Introdução}

Projetos são a mola propulsora para o desenvolvimento das organizações. É através deles que são desenvolvidos novos produtos, processos, serviços e resultados que geram inovação, economia e eficiência que trazem vantagens competitivas.

No entanto, projetos não são instrumentos de mudança simples ou fáceis de executar. Segundo o Chaos Manifesto 2013, apenas 39\% dos projetos executados podem ser considerados um sucesso; $43 \%$ deles são concluídos fora do prazo, orçamento ou qualidade e 18\% falham [Standish Group 2014].

Buscando melhorar estes resultados, as organizações vêm investindo na gerência de projetos. Os resultados vêm aparecendo e o Standish Group (2014) atribui parte dessa melhoria ao crescimento da profissão de gerente de projetos.

O Gerente de Projetos (GP) é um profissional que é, em grande parte, responsável pelo sucesso dos projetos. Entre outras atribuições, a ele cabem as seguintes tarefas: a liderança da equipe do projeto, a negociação com as partes interessadas, o acompanhamento e controle das atividades, e a tomada de decisão. 
Além da complexidade do tema, os ambientes em que projetos são executados são diferentes entre si e estão em constante mudança, exigindo do gerente de projetos que ele esteja sempre procurando dar continuidade a sua capacitação.

Apesar do esforço dispensado com o intuito de melhorar a qualificação dos profissionais da área, a educação convencional vem sofrendo muitas críticas recentemente devido a continuar utilizando metodologias tradicionais que não conseguem mais ganhar a atenção dos alunos, sendo na maior parte do tempo repetitiva e entediante. Por isso pedagogos e pesquisadores estão buscando permanentemente por ferramentas de auxílio ao ensino que possam ser cada vez mais atrativas para a educação tradicional ou corporativa.

Dentre estas ferramentas, os jogos sérios [Michael e Chen 2006] têm se mostrado como fortes candidatos ao auxílio ao ensino por permitirem motivar as pessoas, aproveitando da predisposição que elas têm para jogar, canalizando seu envolvimento, sua necessidade de conquista e realização na construção do conhecimento e novas habilidades.

Nesse contexto, este trabalho propõe um modelo conceitual para jogos voltados ao auxílio dos treinamentos teóricos do gerenciamento de projetos. A partir deste modelo, professores podem apresentar abstrações de situações do mundo real aos seus alunos a fim de trabalharem o processo de tomada de decisões e identificarem as consequências das mesmas.

O documento está organizado da seguinte forma: na seção 2 serão apresentados alguns trabalhos relacionados; a seção 3 introduz o modelo conceitual proposto neste trabalho; na seção 4 será apresentado um estudo de caso de gerenciamento de projetos; na seção 5 serão apresentados os experimentos realizados e os resultados obtidos e a seção 6 apresentará as conclusões e considerações finais.

\section{Trabalhos relacionados}

Bonetti e Wangenheim (2013) mapearam um número significativo de jogos não digitais de gerenciamentos de projetos nos modelos de tabuleiro, de cartas, de peças de montar, mas apenas três jogos em formato digital.

Por sua vez, Paludo e Raabe (2010) analisaram treze jogos digitais para educação em gerenciamento de projetos, concentrando-se especificamente em projetos de software, isto é, de desenvolvimento.

A análise - inédita ou complementar aos autores citados - permite concluir que, a despeito de suas inegáveis qualidades e da contribuição que todos os jogos analisados oferecem a educação do gerenciamento de projetos, ainda é possível compilar as seguintes limitações:

- A grande maioria está disponível exclusivamente na língua inglesa;

- Dois deles limitam-se a alocação de recursos (humanos e materiais): Game Corp e Youth Center Simulation;

- Três apresentam sistemas de perguntas de múltipla escolha que não estavam alinhadas a um roteiro, sendo sempre objetivas (nunca situacionais): Are you a good manager?, Project Management Test e Scrum Scape; 


\section{CBIE-LACLO 2015}

Anais dos Workshops do IV Congresso Brasileiro de Informática na Educação (CBIE 2015)

- Quatro deles focam demasiado na diversão, de modo que o elemento educativo fica em um plano bastante reduzido: Are you a good manager?, Leadersheep, Scrum Scape e Win the Project.

Outro trabalho que merece atenção especial foi proposto por Franco, Lorenzi e Peres (2014): o Castelo da Matemágica. Este trabalho, embora não tenha por objetivo a educação específica do gerenciamento de projetos, propõe um modelo de jogo educacional aplicável a diversas matérias. Além disso, também propõe a elaboração de aventuras textuais educativas com a diferença básica de exigir de um autor eventual os conhecimentos necessários para a elaboração de uma ontologia.

Por fim, é válido registrar que o trabalho proposto aqui pretende atender ao menos seis das 13 recomendações propostas por Paludo e Raabe (2010): estar disponível na web, ser adequado ao ritmo do jogador, fácil utilização, fornecer simulação, estar fundamentado em boas práticas e, principalmente, possibilitar que um instrutor de gerenciamento de projetos, sem conhecimentos de programação, usufrua de sua arquitetura para criar seus próprios jogos para seus alunos.

\section{Decisão de Gerente de Projeto (GP)}

$\mathrm{Na}$ seção anterior, foi demonstrado que as ferramentas existentes para educação em gerenciamento de projetos não apresentam como foco prioritário o processo de tomada de decisão. Além disso, não valorizam o ciclo de vida do projeto de forma que novos conhecimentos técnicos possam ser inseridos, inclusive com contribuição direta da comunidade acadêmica.

Nesse contexto, o presente trabalho propõe uma solução alternativa capaz de suprir as deficiências identificadas: Decisão de Gerente de Projeto (GP) é uma ferramenta concebida para que professores de gerenciamento de projetos construam histórias seguindo um modelo. Tais histórias devem servir de exercício e apresentar abstrações de situações do mundo real que permitam aos estudantes tomarem decisões e conhecerem suas consequências.

Assim, Decisão de GP provê uma arquitetura básica para a construção de histórias cuja aplicação se enquadra nas estratégias de ensino "resolução de exercícios" e "solução de problemas" [Mazzioni 2013]. O máximo aproveitamento do estudante se dá em execução individual em laboratório após receber aulas por exposição teórica.

Os jogadores são auto avaliados a cada decisão tomada durante o jogo e os professores podem fazer avaliações globais a partir da compilação dos resultados individuais identificando, por exemplo, pontos de falhas mais comuns.

Trabalhos envolvendo experimentos com aventuras solo [Carvalho 2011] têm demonstrado que o funcionamento de um livro-jogo pode ser resumidamente ilustrado conforme a Figura 1.

Pode-se concluir que:

- Cada situação apresenta duas ou mais alternativas de decisão;

- Cada decisão leva a uma nova situação-problema ou ao final da aventura;

- A aventura pode ter finais distintos;

- Decisões diferentes podem levar a um mesmo final. 
Decisão de GP provê um modelo baseado nestas conclusões. Para criar uma aventura solo em formato digital que ensine como gerenciar projetos de construção civil, por exemplo, o professor não precisará ter conhecimento em linguagem de programação.

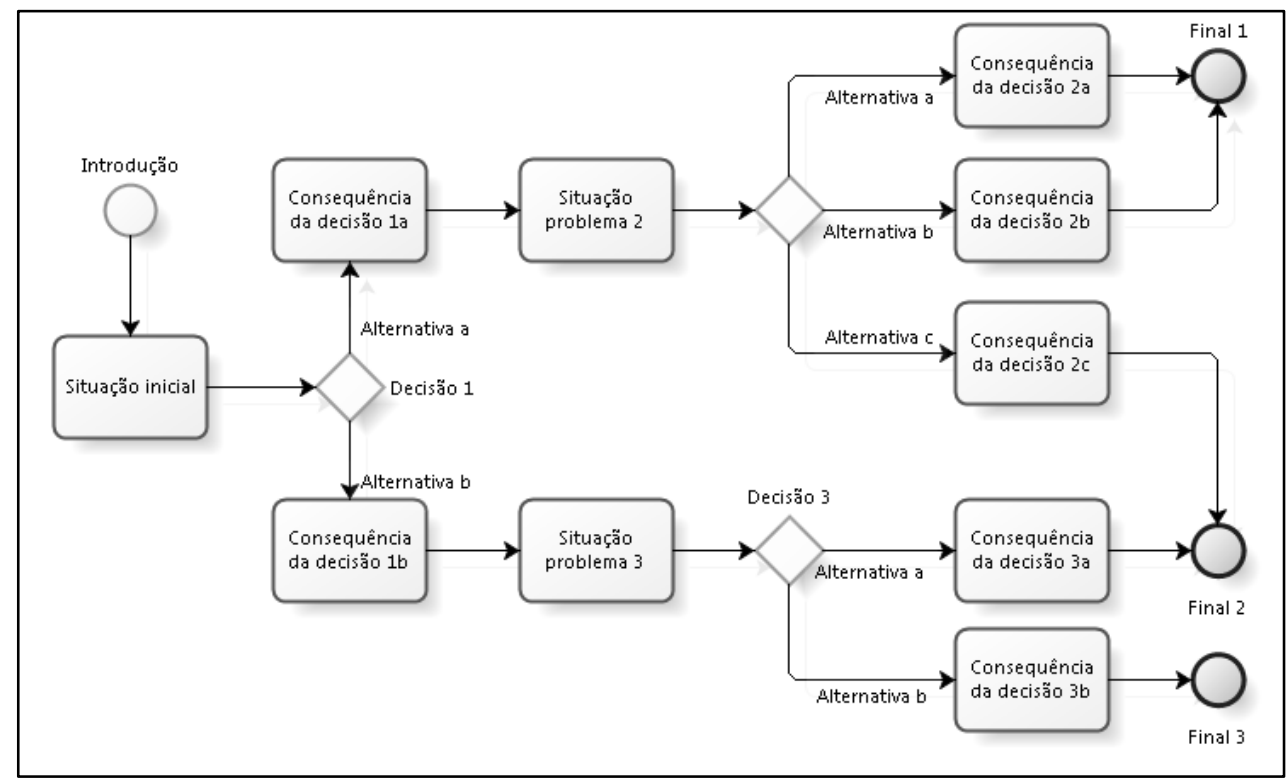

Figura 1. Fluxograma resumido do funcionamento de um livro-jogo. Fonte: desenvolvida pelos autores.

\subsection{Visão do professor ou instrutor de gerenciamento de projetos}

Um professor, para dispor de uma aventura-solo para aplicar junto aos seus alunos deverá acessar um web site no qual seguirá os seguintes passos:

1. Conceber uma história e cadastrar sua introdução;

2. Cadastrar um conjunto de situações problemas;

3. Cadastrar as alternativas de solução e suas respectivas consequências;

4. Encadear as situações problemas, indicando a sequência em que elas devem ser apresentadas;

5. Cadastrar finais possíveis para a história e suas condições de apresentação.

Para facilitar o trabalho do instrutor e enriquecer suas histórias, o professor poderá se valer de experiências compartilhadas por outras pessoas no próprio modelo.

\subsection{Visão do estudante de gerenciamento de projetos}

Uma vez que existam histórias cadastradas, qualquer estudante interessado em gerenciamento de projetos poderá selecionar uma delas e jogá-la. Para isso, acessará o mesmo web site, porém com interface elaborada para a execução da partida, isto é, uma versão mobile que simule o comportamento das aventuras solo.

\subsection{Modelo conceitual}

Com o domínio do funcionamento básico dos livros-jogos, foi possível definir o modelo conceitual da plataforma a ser desenvolvida, conforme Figura 2. Este modelo é a abstração de mais alto nível de como os dados serão organizados de modo a prover os jogos e executar as partidas.

O modelo conceitual está organizado em três seções como apresentado na Figura 2, que serão detalhadas adiante. Nesta figura, os retângulos identificam as entidades: os 
CBIE-LACLO 2015

Anais dos Workshops do IV Congresso Brasileiro de Informática na Educação (CBIE 2015)

elementos básicos ao funcionamento da plataforma; e os losangos, os relacionamentos: as associações existentes entre as entidades.

A interpretação inicial a se fazer do modelo é a seguinte:

- Um professor cria um jogo encadeia situações problemas que propõe alternativas de solução. Um jogo contempla um ou mais finais;

- Um usuário (estudante) joga uma partida que executa um jogo. A partida registra um log que rastreia as alternativas escolhidas pelo usuário;

- Uma situação problema pode ser embasada em experiências compartilhadas por membros da comunidade.

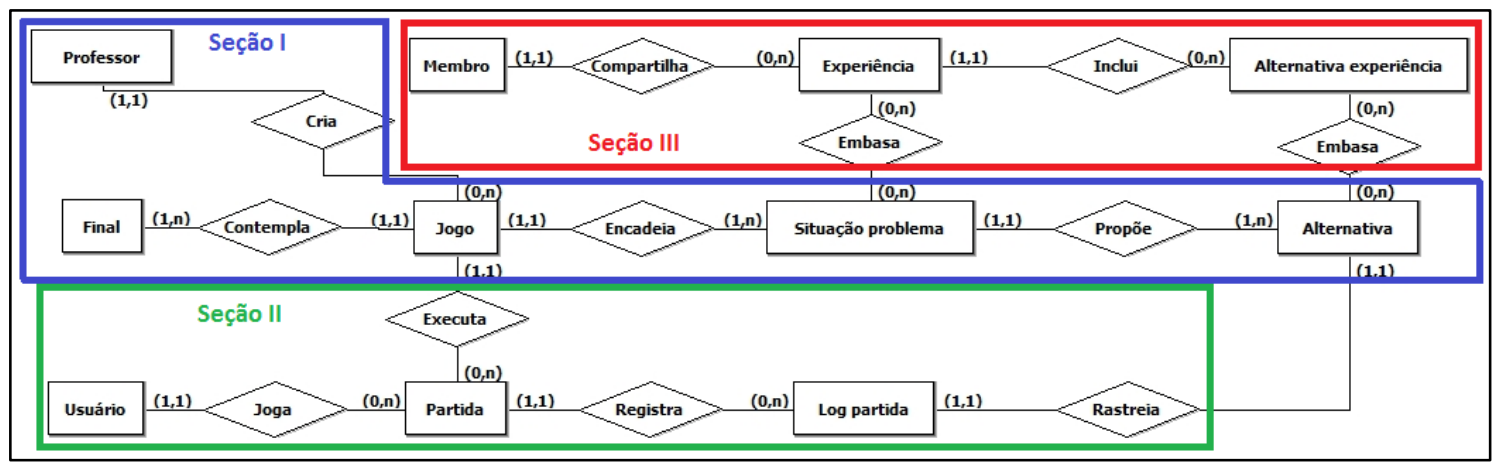

Figura 2. Modelo conceitual de Decisão de GP, organizado em três seções: I - O jogo, II - A execução do jogo e, III - A contribuição dos interessados. Fonte: desenvolvida pelos autores.

A Seção I, destacada em azul, corresponde às informações que devem ser preenchidas por um professor de gerenciamento de projetos para cadastrar um jogo válido. Suas entidades foram especificadas conforme a seguir:

- Professor: descreve o usuário específico da solução, capacitado e responsável pela criação e cadastro dos jogos.

- Jogo: descreve um exercício prático registrado por um professor de gerenciamento de projetos. Seus principais atributos são: título, introdução e valor inicial do KPI (indicador de desempenho dentro do jogo).

- Situação problema: descreve cada situação que será apresentada para o jogador, passível de uma tomada de decisão.

- Alternativa: descreve cada opção que pode ser tomada pelo jogador diante de cada situação problema. Seus principais atributos são: descrição, consequência, efeito sobre o KPI e passo seguinte.

- Final: descreve as conclusões do exercício e em quais circunstâncias devem ser apresentadas. Seus atributos principais são: título e valores KPI mínimo e máximo (que determinam qual final deve ser exibido).

A Seção II da Figura 2, destacada em verde, registra a participação do jogador no processo. Ele realiza apenas duas ações no jogo: inicia uma partida e toma decisões, na primeira ele faz existir uma partida e na segunda registra um log das suas decisões. Para que ambas tenham efeito, é necessário o uso da seguinte estrutura:

- Usuário: identifica o estudante jogador. 
CBIE-LACLO 2015

Anais dos Workshops do IV Congresso Brasileiro de Informática na Educação (CBIE 2015)

- Partida: descreve a execução de um jogo por um jogador e registra o controle do valor do KPI atual que vai ser comparado aos finais possíveis para a partida.

- Log partida: controla cada decisão, isto é, cada alternativa escolhida ao longo de uma partida.

A Seção III da Figura 2, destacada em vermelho, prevê a possibilidade de contribuição informal de qualquer interessado, que pode vir a servir de referência para a criação de histórias por um instrutor. Ela corresponde a uma versão simplificada das estruturas apresentadas como "situação problema" e "alternativa".

- Membro: descreve um usuário disposto a compartilhar uma experiência que possa vir a ser usada por um ou mais professores.

- Experiência: apresenta uma situação problema vivida (ou criada) por um membro da comunidade que contribuiu espontaneamente.

- Alternativa da experiência: descreve as opções que o membro da comunidade acredita que existiam quando ele viveu aquela experiência.

\section{Estudo de caso: GP de TI - Beta}

\subsection{Protótipo}

Definido o modelo conceitual, foi possível escrever um protótipo em papel do jogo a ser desenvolvido. Cada situação problema foi ilustrada em um ou mais cartões de papel numerados, sequenciados em uma árvore escrita em uma folha de papel à parte, escondida do jogador para controlar o fluxo da história.

Três gerentes de projeto foram voluntários para o teste do protótipo em papel e aprovaram a experiência inicial apresentando críticas construtivas que foram consideradas na construção do protótipo em software.

Para validação do modelo na versão em software, foi implementado um banco de dados que contemplou as seções I e II do modelo conceitual apresentado na Figura 2. A Seção III foi preterida neste momento devido ao propósito do teste de certificar que a estrutura primordial da ferramenta atendesse suas necessidades básicas, que são: cadastrar jogos e executar jogos.

Haja vista que a história inicial seria cadastrada pelo autor deste trabalho, a interface para cadastro de jogos não foi desenvolvida de forma amigável. Valendo-se dos recursos providos pelo próprio Sistema Gerenciador de Banco de Dados MySQL, através de sua interface phpMyAdmin.

O primeiro jogo foi então cadastrado, tratando-se de uma versão aprimorada daquela especificada no protótipo em papel. A versão contemplava: 18 situações problemas com 52 alternativas e abrangendo 9 das 10 áreas de conhecimento. Sua descrição a seguir, baseia-se no modelo proposto por Jesse Schell (2010).

\subsection{Características gerais}

O jogo está caracterizado da seguinte forma: gênero: simulação/RPG; categoria: educacional; plataforma: web; público-alvo: adulto, jogadores eventuais, estudantes de gerenciamento de projetos; duração estimada: 15 minutos e; requisitos mínimos: navegador compatível com HTML5 e Javascript. 
CBIE-LACLO 2015

Anais dos Workshops do IV Congresso Brasileiro de Informática na Educação (CBIE 2015)

\subsubsection{Enredo}

O jogo se passa numa empresa de desenvolvimento de software. O jogador deve assumir o papel de gerente substituto de um projeto de software mobile. Caso atenda às expectativas de seu contratante, ele será recompensado com a contratação como gerente de projetos efetivo da empresa.

\subsubsection{Gameplay}

Ao iniciar o jogo, uma história é apresentada ao jogador (Figura 3a), convidando o mesmo a ingressar em um projeto. Nessa ocasião é apresentado um fator crítico que determinará o grau de sucesso do jogador ao final da partida. A partir daí, o jogo apresenta sequencialmente situações problema para tomada de decisão que refletem no desempenho do jogador. A partida acaba com a conclusão do projeto, e a contratação do jogador sendo condicionada pelo cumprimento ou não do prazo concedido.
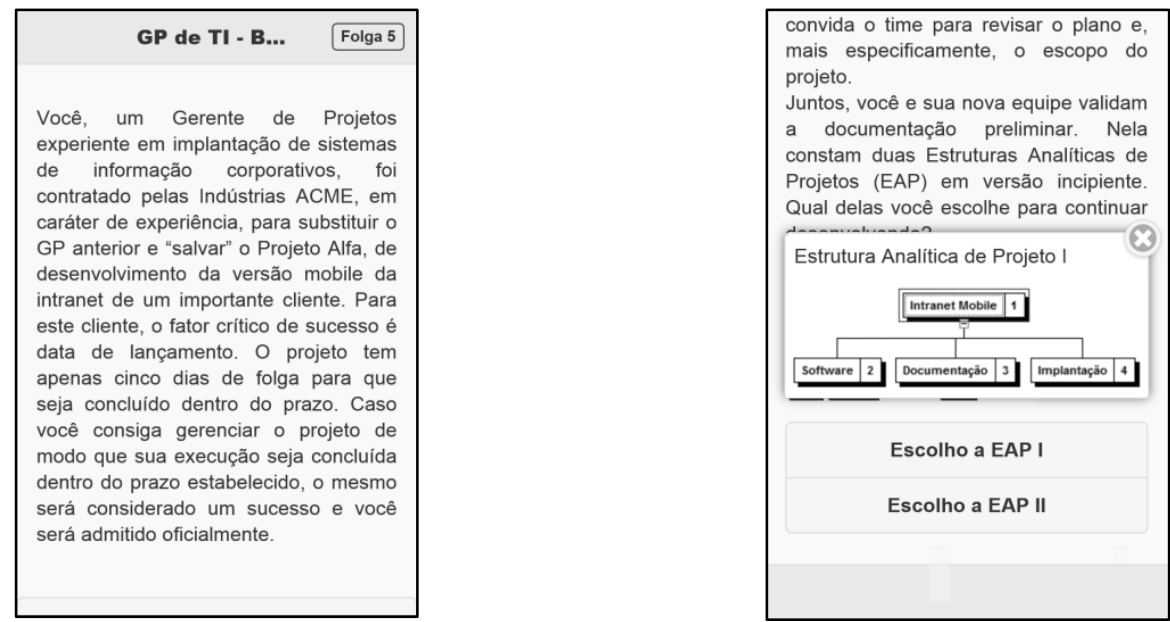

Figura 3. Exemplos de interface de apresentação do jogo GP de TI - Beta: a) história do problema e definição do objetivo; e b) pop-up de botões de múltipla escolha para tomada de decisão. Fonte: desenvolvidas pelos autores.

\subsubsection{Mecânica}

O objetivo primário do jogo é concluir o projeto proposto dentro de um prazo estabelecido de cinco dias, no qual folgas podem ser adquiridas ou perdidas em virtude das decisões tomadas pelo jogador.

Folga é um termo técnico da gerência de projetos que simplificadamente indica quanto tempo uma atividade ou entrega pode atrasar sem comprometer o cronograma [PMI 2013].

Cada situação apresentada baseia-se na literatura de gerenciamento de projetos, em informações compartilhadas em fóruns ou inspiradas em outros jogos. Cada decisão tem como consequência um bônus ou penalidade a ser aplicado no número de dias de folga do projeto.

Adicionalmente aos dias de folga ganhos ou perdidos, o jogador pode ser contemplado com medalhas que significam aquisição de habilidades específicas [Vianna et. al 2013].

\subsubsection{Interface}


A interface utilizada é enxuta para permitir que a tomada de decisão seja bem embasada, uma vez que, as situações problemas tendem a ter textos longos. Minimizando os elementos da interface é possível apresentar texto suficiente com o mínimo de rolagem de páginas.

A Figura 3b ilustra a interface básica: a situação problema para tomada de decisão é apresentada na forma de texto, eventualmente seguida de imagens. As alternativas que o jogador tem em cada situação são apresentadas em botões. Um clique/toque leva para a consequência da decisão tomada seguida da apresentação da situação problema seguinte. Um ícone localizado na extremidade superior esquerda da tela (Figura 4a) abre um menu que apresenta as medalhas disponíveis no jogo. Um toque/clique sobre uma das medalhas amplia sua imagem numa janela pop-up apresentando instruções de como conquista-la, conforme Figura $4 b$.
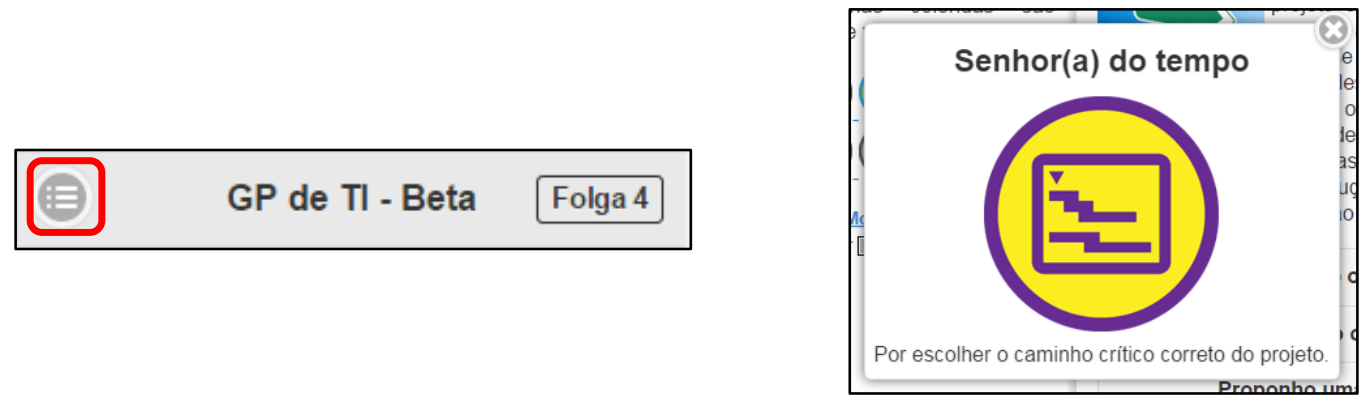

Figura 4. Recursos da interface: a) cabeçalho do jogo destacando menu e o contador de folgas; e b) medalha "Senhor(a) do tempo", ofertada ao jogador que escolhe o caminho crítico correto, no momento do jogo em que esta decisão deve ser tomada. Fonte: desenvolvidas pelos autores.

\section{Experimentos e avaliação da solução}

O protótipo desenvolvido foi utilizado para realizar experimentos a fim de validar o modelo proposto. Esta validação se deu pela publicação de uma versão beta de forma pública na internet, e sua divulgação através de grupos sobre gerência de projetos na rede social LinkedIn®.

Ao total foram iniciadas 111 partidas, de forma anônima, por participantes da rede social envolvidos no tema do gerenciamento de projetos. Destas partidas, 71 $(63,96 \%)$ foram jogadas até o final. Destas, em $51(71,83 \%)$ partidas os jogadores obtiveram sucesso e em $20(28,17 \%)$ fracassaram.

Ao final de cada partida o jogador foi convidado a responder um pequeno questionário sobre o que achou da experiência. A compilação dos resultados mais relevantes é apresentada a seguir e baseia-se num total de 84 questionários respondidos.

Sobre o perfil dos jogadores quanto à gerência de projetos, pergunta na qual o participante podia escolher mais de uma opção, 64,81\% se declararam estudantes, $40,74 \%$ se declararam gerentes de projetos e apenas $3,7 \%$ se declararam instrutores.

A Figura 5 compila o resultado da avaliação. Dos entrevistados, 93\% concordam total ou parcialmente que a atividade simula situações reais, o que sugere que as situações de tomada de decisão apresentadas são verossímeis. Além disso, $90 \%$ concordam total ou parcialmente que o jogo ajuda a fixar conhecimentos, nos levando a conclusão que ele cumpre com o seu propósito educativo. Por outro lado, 75\% 
concordam total ou parcialmente que a atividade serve como passatempo/diversão, o que significa que já existem elementos de engajamento, mas eles ainda são passíveis de melhoria.

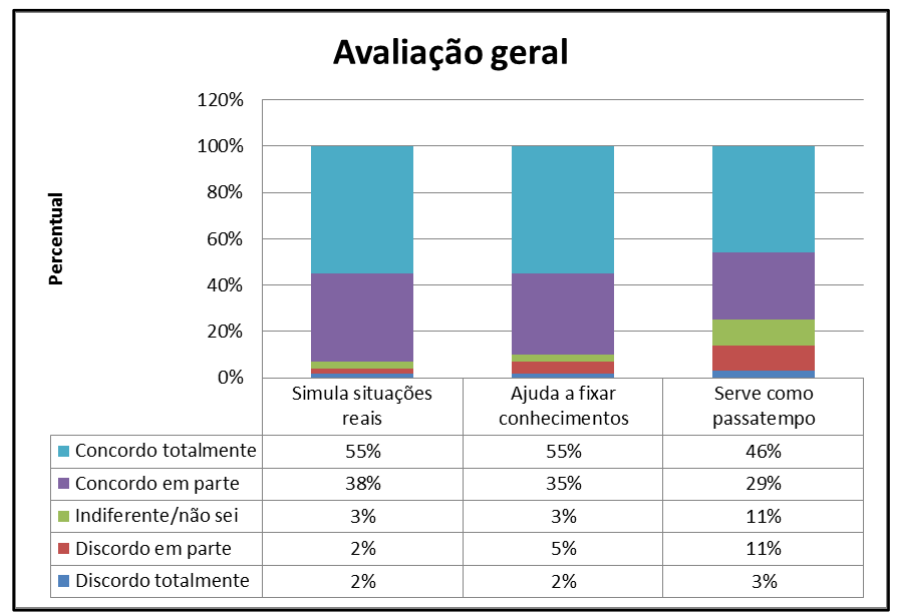

Figura 5. Compilação do resultado da avaliação.

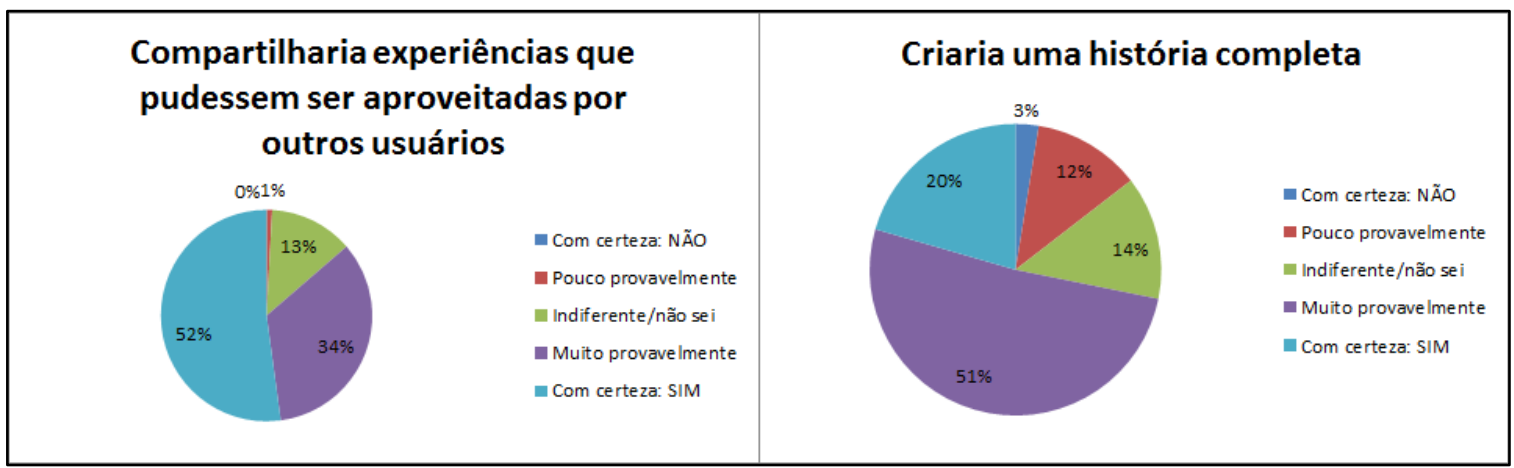

Figura 6. Avaliação de intenção de contribuir para a geração de conteúdo através da ferramenta a ser desenvolvida.

Por fim, em mais uma característica que sugere o engajamento, mais de $85 \%$ dos participantes afirmaram que poderiam contribuir com a criação de novas histórias e mais de $70 \%$ do total poderiam criar suas próprias histórias, caso houvesse uma ferramenta adequada para fazê-lo (Figura 6).

\section{Conclusões}

Jogos são excelentes recursos educacionais para todas as áreas de conhecimento, em especial para o gerenciamento de projetos.

A mecânica da aventura solo, particularmente centrada na tomada de decisão, mostrou-se adequada para a simulação de projetos.

Tais constatações embasaram a principal contribuição deste trabalho: um modelo conceitual para criação de jogos digitais para educação em gerenciamento de projetos sem a necessidade de conhecimento de programação.

O desenvolvimento de Decisão de GP se mostra promissor e a ferramenta já demonstra alguma capacidade de engajamento. A mecânica simples facilita sua 


\section{CBIE-LACLO 2015}

Anais dos Workshops do IV Congresso Brasileiro de Informática na Educação (CBIE 2015)

compreensão e domínio, o que pode contribuir para seu crescimento através da participação da comunidade de gerenciamento de projetos.

Ficam como oportunidades futuras, entre outras:

- O desenvolvimento da interface amigável para o cadastro de novas histórias por professores de gerenciamento de projetos;

- O mapeamento das decisões tomadas pelos jogadores, para determinar padrões comportamentais e psicológicos em gerentes de projetos e;

- A implementação de uma interface mais rica e envolvente, funcional em múltiplas plataformas, além de apps específicos para os principais dispositivos móveis.

Além dessas, presume-se que a adaptação e aplicação do modelo em outras áreas de atuação quer sejam de gestão ou não, poderia resultar em igual sucesso.

\section{Referências}

Bonetti, T. M. e Wangenheim, C. G. von (2013) Desenvolvimento de um repositório de jogos educacionais para o ensino de gerenciamento de projetos. Florianópolis: Anais eletrônicos do CBIE.

Carvalho, W. T. de (2011) Uso de uma aventura-solo como ferramenta didática para o ensino de análise combinatória. Rio de Janeiro: 2011.

Franco, T. C.; Lorenzi, F. e Peres, A. (2014) Castelo da Matemágica: uma adventure textual aplicado ao ensino. Dourados: Anais eletrônicos do CBIE.

Mazzioni, Sady. (2013) As estratégias utilizadas no processo de ensino-aprendizagem: concepções de alunos e professores de ciências contábeis. Chapecó: Revista Eletrônica de Administração e Turismo, V.2, n.1, jan-jun.

Michael, D. and Chen, S. (2006) Serious Games: Games that Educate, Train and Inform. Thomson Course Technology PTR.

Paludo, L. e Raabe, A. (2010) Análise de jogos educativos de computador para gerência de projetos de software. Disponível em http://www.lbd.dcc.ufmg.br/colecoes/wei/2010/0015.pdf. Último acesso em 20/05/2015.

Project Management Institute (2013) Um guia do gerenciamento de projetos (Guia PMBoK®). 5 ed. Newtown Square: Project Management Institute Inc.

Schell, J. (2010) A arte de game design: O livro original: Rio de Janeiro: Campus/Elsevier.

Souza, A. V.; Chagas, F. A.; Silva, C. E (2011). Jogos de empresas como ferramenta de treinamento e desenvolvimento. Revista Brasileira de Administração Científica. Aquidabã, V.2, n.2, p 05-23.

Standish Group (2014) Chaos manifesto 2013: think big, act small. Disponível em http://www.versionone.com/assets/img/files/ChaosManifesto2013.pdf. Último acesso em $20 / 05 / 2015$.

Vianna, Ysmar; et al.. Gamification, Inc (2013), como reinventar empresas a partir de jogos. Rio de Janeiro: MJV Press. 